\title{
Histoplasma Variation and Adaptive Strategies for Parasitism: New Perspectives on Histoplasmosis
}

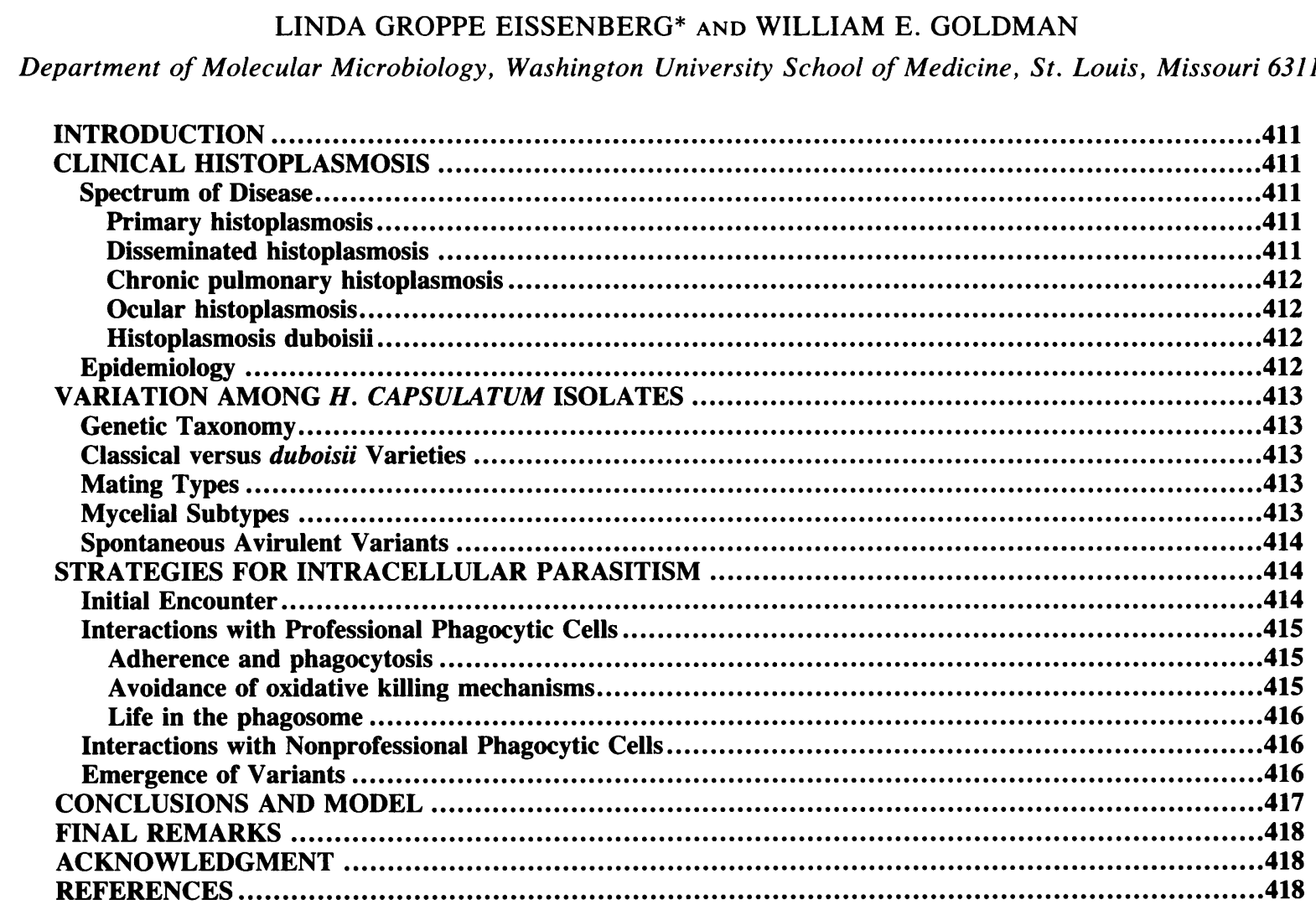

\section{INTRODUCTION}

It is no surprise that numerous reviews have been written on Histoplasma capsulatum, a dimorphic fungus that causes a broad spectrum of disease. Rather than reiterate, this article will attempt to relate the scope of disease both to natural variations in characteristics of the infecting organism and to adaptations this microbe makes in response to various microenvironments. While the immune system undoubtedly plays an important part in controlling histoplasmosis, recent work underscores the role that the fungus itself plays in determining the type and severity of disease. The focus here will be on the adaptations that $H$. capsulatum makes during interactions with its host cells and how these changes are manifested in different forms of disease.

\section{CLINICAL HISTOPLASMOSIS}

\section{Spectrum of Disease}

Primary histoplasmosis. Most individuals infected with $\boldsymbol{H}$. capsulatum experience an inapparent or mild disease that might be confused with influenza. These people are identified primarily on the basis of demonstrated cellular immunity to histoplasmin (an extract of fungal antigens) following a

\footnotetext{
* Corresponding author.
}

skin test. Relatively few infected persons are inflicted with the similar, but more severe, symptoms accompanying acute histoplasmosis. Following either type of primary infection, radiological examination often reveals multiple focal lesions within the lungs. These granulomas, which are often calcified, are believed to represent the body's attempt to restrict spread of the infection. Within a given person, all such lesions share the same size and histological characteristics. This observation suggests that a single exposure to multiple spores, rather than repeated reinfections, probably induces all of these granulomas (110).

It has been shown clinically that fungemia can occur without leading to obviously disseminated disease (89). In concordance, experimental models demonstrate that during primary histoplasmosis the organism disseminates by lymphohematogenous spread to reticuloendothelial organs such as the lymph nodes, spleen, liver, and bone marrow (for a review, see reference 110). Regardless of whether inapparent or overt histoplasmosis occurs, scars are left in the spleen or liver during at least $70 \%$ of human infections (119). Consequently, the presence of multiple healed calcifications within the spleen is sometimes the first indication that benign dissemination of $\boldsymbol{H}$. capsulatum has occurred (110).

Disseminated histoplasmosis. In patients with clinically apparent disseminated disease, lesions may appear not only in the reticuloendothelial system but also in many organs that contain relatively few macrophages (e.g., skin, heart, 
brain, adrenal glands, oropharyngeal cavity, and gastrointestinal tract). Extensive colonization of such a wide variety of tissues is presumably a result of the depressed cellular immunity associated with disseminated histoplasmosis (96). When patients recover from this form of the disease, $H$. capsulatum is not necessarily eliminated from the body. Instead, a latent infection can be established and can eventually "reactivate," leading to relapsing disseminated disease.

Reactivation may also occur following mild or inapparent infections. For example, apparently healthy people with no history of histoplasmosis can move out of areas in which the disease is endemic and then show symptoms of disease months to years later. Immunosuppression due to chemotherapy $(22,37,82)$ or $\operatorname{AIDS}(41,62,71)$ is clearly associated with some but not all instances of reactivation. A transient alteration in the physiology or immune status of an individual might explain the additional cases.

Chronic pulmonary histoplasmosis. Chronic pulmonary histoplasmosis predominantly occurs in white middle-aged males, especially smokers. These individuals frequently have centrilobular or bullous emphysema (39), which leads to speculation that these conditions may provide particularly hospitable environments for the fungus. Such microenvironments may even allow a persistent infection to be established, thus explaining the chronic nature of the disease. Alternatively, different strains or variants of the fungus might repeatedly infect these especially susceptible hosts, perhaps explaining the heightened immune response often seen during this illness. Inapparent infections may also occur, since $20 \%$ of patients in one study (39) had no symptoms upon diagnosis.

Ocular histoplasmosis. Visual problems sometimes occur in people who react with histoplasmin, especially individuals having human leukocyte antigen complex types B7 $(10,35)$ and DRw2 (79). Many afflicted persons have no history of active disease, suggesting that the organism can disseminate to the eyes even during mild and inapparent infections. In individuals with overt disseminated disease, it is not uncommon to find $H$. capsulatum in the eyes $(19,36,88,107)$. However, while these patients sometimes have panophthalmitis, they rarely show ocular abnormalities (31). Since patients with obviously disseminated disease also have decreased cellular immunity, it has been suggested that an intact immune system may play some role in the development of ocular histoplasmosis syndrome (107).

Lesions in the eyes of patients with ocular histoplasmosis syndrome are distinct from those seen in other infected organs. In the latter, the fungus literally becomes walled off from the surrounding tissues within granulomas, and so it is common to see yeasts (or their dead bodies) inside these structures. In contrast, Makley et al. (70) proposed that the scars and neovascularization seen in patients with ocular histoplasmosis syndrome are the result of an effort by the body to heal a wound in the basal lamina of the choroid (Bruch's membrane). The initial damage to the membrane presumably occurs as an indirect consequence of infection by $H$. capsulatum. Thus, one would not expect to find the fungus within these lesions, and in fact it has been difficult to do so either through culturing or by histological techniques. However, Makley et al. (70) report that they were able to obtain the organism from the choroid epithelium adjacent to the lesions in two patients who had symptoms of ocular histoplasmosis syndrome for several years. This suggests that the yeast form may be able to establish a persistent yet inapparent infection of the eyes.
Similarly inapparent ocular lesions that are detectable only by administering certain visual tests reportedly occur in humans $(31,104)$. Clues to the origin of these phantom lesions may be gained from the observations made in an experimental model. Smith et al. (112) found ocular lesions within the eyes of primates shortly after inoculation but had great difficulty finding either the same lesions or healed scars 1 month later.

Histoplasmosis duboisii. It is believed that histoplasmosis due to $\boldsymbol{H}$. capsulatum var. duboisii is contracted only in Africa. Unlike histoplasmosis resulting from infection by the classical strains of the organism, there is generally little colonization of the lung during primary infection by the duboisii variety. However, more extensive involvement of the lung occurs during chronic pulmonary and disseminated disease (for a review of histoplasmosis duboisii, see reference 97). In contrast to classical $\boldsymbol{H}$. capsulatum strains, this variety seems to have a predilection for the lymph nodes, skin, skull, scapula, and jaw. The relative avirulence of the $H$. capsulatum var. duboisii strains, at least in experimental animals $(74,109)$, may have some bearing on their wellknown propensity for establishing persistent infections. For example, animals captured and moved out of Africa have been kept in captivity for months to years before overt disease occurred $(74,121)$. Similarly, during a persistent infection of humans by this variety, an individual lesion can go through alternating periods of quiescence and recrudescence for several years (see reference 97).

\section{Epidemiology}

H. capsulatum is a dimorphic fungus with a vegetative form that exists as hyphae and conidia (spores) within the soil and a yeast form that exists at body temperatures. With rare exceptions, this fungus infects its host via the respiratory route. Infections often occur after human disruption of the soil during farming, property upkeep, or construction, all of which tend to aerosolize the hyphae and conidia of the organism. In an experimental model, a single exposure to aerosolized soil containing $H$. capsulatum microconidia was sufficient to infect 60 to $80 \%$ of the exposed guinea pigs. Following a second exposure, $100 \%$ of the animals were infected. Macroconidia were ineffective in establishing infection (66). It is noteworthy that both the tendency to conidiate and the proportion of the two types of conidia are strain dependent.

At one time $\boldsymbol{H}$. capsulatum was believed to be endemic only to river valleys in temperate regions receiving large amounts of rainfall, especially the Mississippi and Ohio River valleys in the United States. However, in 1965, Campbell (16) predicted that $\boldsymbol{H}$. capsulatum would be found in nearly every habitable area of the world. This prediction was based on the fact that, even where the organism is supposedly nonendemic, there are small geographic locations in which people show reactivity to histoplasmin. Campbell's prediction has been borne out (for a review, see reference 96), and $\boldsymbol{H}$. capsulatum has been found even in arid regions under irrigation (55).

It is not clear why epidemics of histoplasmosis occur in areas where the fungus is endemic. The vast majority of the populace has demonstrable cell-mediated immunity to histoplasmin and so should be somewhat resistant to disease. However, in some instances, most exposed individuals have succumbed to infection (105). This paradox is generally explained as the result of reinfection by massive numbers of conidia. Curiously, in a 9-year experiment by Procknow 
(91), up to 33 attempts to reinfect dogs with $\boldsymbol{H}$. capsulatum failed to produce either overt disease or reactivation of old lesions.

Assuming that the dog model accurately reflects what occurs in humans, it is difficult to understand how reinfection could occur. Perhaps a second infection is initiated by phenotypically different organisms to which the individuals are immunologically naive. This explanation predicts that, within areas where histoplasmosis is endemic, there are microenvironments that harbor a strain or variant of the organism different from the one most prevalent in the community. Peculiarities of the soil might favor certain strains or even induce variants with altered antigenicity or physiology.

H. capsulatum has been isolated from soil as much as 38 $\mathrm{cm}$ beneath the surface (69). However, conidia are generally found only in the relatively loose topsoil to a depth of 0.75 $\mathrm{cm}$. Such a location may facilitate aerosolization. By $1.5 \mathrm{~cm}$ below the surface, vegetative growth is more common and more abundant (38). Human or animal disruption of the soil might thus aerosolize hyphal fragments, which are also capable of initiating infections. Epidemics might result if unusual phenotypes or strains are exposed.

There is also clinical evidence implying that organisms with different phenotypes inhabit the same geographic area. A recent study has shown that class 1 isolates (see next section) have been found in patients living in the St. Louis, Mo., area (113), where class 2 organisms are believed to be in preponderance $(113,114,120)$. This observation suggests that classes 1 and 2 may have some habitats in common. However, it has not been possible to prove such an overlap, since no soil isolate has yet fallen into class 1 .

The inability to obtain class 1 strains from the soil may indicate that their physiology or nutritional requirements differ from those of the more conventional strains $(77,113)$. In one study of $18 \mathrm{H}$. capsulatum isolates, their individual nutrient requirements varied considerably as the organisms adapted to the incubation temperatures, $\mathrm{pHs}$, and humidity levels at which they were incubated (109). Likewise, there may be deficiencies in the existing methods of surveying the soil, as these methods are not always in agreement. In one investigation comparing three different techniques, $\boldsymbol{H}$. capsulatum was isolated by all three methods only $5 \%$ of the time (78).

\section{VARIATION AMONG $H$. CAPSULATUM ISOLATES}

\section{Genetic Taxonomy}

Taxonomic studies based on the restriction endonuclease digestion patterns of mitochondrial and ribosomal DNA $(113,114,120)$ indicate that there is at least some geographical constraint on the type of strains that can be isolated. Class 3 organisms occur in Central and South America, while class 2 isolates predominate on the North American and African continents. Only one class 4 strain, isolated from Florida soil, has been described to date, and one strain of the duboisii variety was found recently to fit into none of the previously described classes (30).

Class 1 organisms form a distinctive set of strains in that they have been isolated from somewhat unusual patients: three from patients with AIDS in the midwestern United States (113), one from a 13-year-old boy in a region of California where the fungus is not endemic (strain UCLA 531R [30, 115]), and one from an octagenarian who had disseminated disease with extensive joint and vaginal in- volvement (the Downs strain [33]). The last patient most likely had some degree of immunosuppression due to her age. By definition, the patients with AIDS were immunodeficient. Since trauma has been cited as a potential source of decreased immunity, it was also suggested that the boy, who had recently been in an accident resulting in the removal of a kidney, may have suffered from transiently depressed immunity (115).

With the exception of strain UCLA 531R (which has not yet been tested), all class 1 strains have been avirulent for mice (113). It seems possible that these strains are also relatively avirulent in humans and cause disease only in immunosuppressed individuals. In immunocompetent persons, class 1 strains may readily establish inapparent yet persistent infections. Disease would then be seen only if the host subsequently became immunosuppressed or experienced some other undefined change in metabolism.

\section{Classical versus duboisii Varieties}

Histological studies frequently reveal very large yeasts (up to $20 \mu \mathrm{m})$ in patients with histoplasmosis caused by $\boldsymbol{H}$. capsulatum var. duboisii (see preceding section). $H$. capsulatum yeasts from the classical strains are almost always 2 to $4 \mu \mathrm{m}$ in size when observed in the lungs. However, the classical strains can also form large yeasts in vivo (25), and $H$. capsulatum var. duboisii may be more related to those that do so with greater alacrity. Beginning with Darling in 1906 (21) investigators have repeatedly found a wide range of morphologies for the classical strains, primarily in nonpulmonary tissues. Not only large yeasts (5 to $20 \mu \mathrm{m})$ but also dumbbell shapes (7), germination tubes on yeasts (7), and actual hyphal forms $(7,52,80)$ have been reported to be interspersed with more normally shaped organisms. Darling (21), who recorded several biazarre morphologies, was influenced by these shapes to identify the organism as a protozoan.

\section{Mating Types}

While the two mating types of $\boldsymbol{H}$. capsulatum (+ and -) appear at an equal frequency in the soil, the - type is seven times more common among clinical isolates (64). This difference may reflect the greater ease with which the - mating type mycelia convert to yeasts in vitro. However, the + mating type was isolated just as often as the - type from individuals with predisposing immunological problems who experienced overt disseminated disease (63). This suggests that, while the two phenotypes are equally capable of causing disease in the immunologically crippled host, the + phenotype is less well equipped to do so in the normal individual.

\section{Mycelial Subtypes}

Cultures of $H$. capsulatum can be separated into two hyphal colony types: the A (albino) type has white aerial hyphae and smooth macroconidia, and the B (brown) type has sparse thin hyphae with masses of tuberculate macroconidia (4). In conventional laboratory culture, the B type is spontaneously and irreversibly overtaken by A-type mycelia (5), although more natural culture medium (e.g., containing bird or bat guano) can select for the B type even from apparently pure A-type cultures (9). Thus, the organic content of soil may have substantial influence over the mycelial type of resident $\boldsymbol{H}$. capsulatum strains. 
Although some reports have claimed that the B type was more virulent than the corresponding A type for a given strain, mouse virulence studies have failed to show a consistent significant difference among B/A pairs $(17,118)$. However, these tests are all based on intravenous inoculation of the yeast form, thus neglecting differences in infectivity that might be due to production of different hyphal or conidial types. Such factors could affect the efficiency of aerial transmission or even the deposition within large or small airways. In this respect, the environmentally triggered conversion of $B$ to $A$ (or vice versa) may have profound implications for the emergence of epidemics (see subsection, Epidemiology) and for influencing the inoculum size during exposure.

\section{Spontaneous Avirulent Variants}

One of the common characteristics of $H$. capsulatum yeast cells is the formation of large aggregates in broth culture. This feature prompted Klimpel and Goldman (59) to enrich for a nonclumping population of yeasts in successive transfers of liquid cultures. When plated on solid medium, these spontaneous variants form "smooth" colonies, in contrast to the highly convoluted ("rough") wild-type colonies. Unlike the B/A mycelial morphological difference, this rough-smooth variation is distinguishable only in the yeast phase.

Virulence testing by intravenous inoculation of mice revealed that smooth variants are essentially avirulent (59). In contrast to the $\mathrm{B} / \mathrm{A}$ difference in mouse virulence, the comparison of $50 \%$ lethal doses $\left(\mathrm{LD}_{50}\right)$ for rough and smooth strains is quite dramatic; in fact, the high $\mathrm{LD}_{50}$ for smooth strains is no different from the $\mathrm{LD}_{50}$ for any heat-killed $H$. capsulatum strain. In vitro, rough strains can destroy macrophage monolayers in a matter of days, but the smooth variants are unable to do so even after 3 weeks in coculture (30).

Later work demonstrated a biochemical correlate of this rough-smooth phenotype. Although cell-associated proteins from matched rough and smooth strains appear identical (59), a major difference lies in the cell wall polysaccharides. Smooth isolates lack the $\alpha-(1,3)$-glucan normally present in chemotype II strains of $H$. capsulatum (60). Earlier work had already established two major $\boldsymbol{H}$. capsulatum serotypes with distinct cell wall compositions (90), and corresponding chemotypes were first described by Domer (24). The distinct chemotypes were later confirmed by Reiss (95) with enzymatic digestion of cell wall polysaccharides. Chemotype I cell walls contain chitin and $\beta$-glucans, whereas chemotype II cell walls have substantially less chitin but also contain $\alpha$-(1,3)-glucan. Most $\boldsymbol{H}$. capsulatum strains, including $\boldsymbol{H}$. capsulatum classes 1 and 3 as well as strains of $H$. capsulatum var. duboisii and $\boldsymbol{H}$. farciminosum, are chemotype II $(30,98)$. The generation of stable smooth variants is a reproducible event that occurs spontaneously in all chemotype II strains of $\boldsymbol{H}$. capsulatum tested (including $\boldsymbol{H}$. capsulatum var. duboisii).

The spontaneous disappearance of a virulence-associated phenotype during culture has many precedents among pathogenic organisms, and phase variation is a common theme linked with adaptation of different environments (both outside and inside of hosts). Culture-associated loss of $\alpha$-(1,3)-glucan had been seen previously during extended in vitro passage of $\boldsymbol{H}$. capsulatum (99), and this loss probably was due to the progressive accumulation of smooth variants in cultures being transferred without single-colony cloning.
In the case of fungi, this particular variation may be of more generalized importance. Spontaneous variants or mutants of Paracoccidiodes brasiliensis also show a correlation of virulence with cell wall $\alpha$-(1,3)-glucan content (100-102).

As mentioned earlier, not all wild-type $H$. capsulatum strains have $\alpha-(1,3)$-glucan in their cell walls, yet these strains (chemotype I, class 2 ) are virulent for both mice and macrophages (30). Thus, $\alpha-(1,3)$-glucan does not appear to be a requirement for $\boldsymbol{H}$. capsulatum virulence; alternatively, undefined culture conditions or in vivo signals may be important in modulating $\alpha$-(1,3)-glucan production in chemotype I strains. It is also not clear whether $\alpha-(1,3)$-glucan itself is a virulence determinant or is merely correlated with virulence in chemotype II strains. This polysaccharide is present in coarse fibers on the outer surface of yeast cells (56), and it may contribute to protection of yeasts within phagolysosomes (see below). Alternatively, the contribution of $\alpha$-(1,3)-glucan to the cell wall architecture could be important in the presentation of other virulence factors that are present on the surface or released by the organisms.

\section{STRATEGIES FOR INTRACELLULAR PARASITISM}

\section{Initial Encounter}

Mammalian hosts are exposed to $H$. capsulatum when they inhale conidia and hyphal fragments from inhabited soil; there are no recorded cases of transmission via exposure to the yeast cells from infected individuals. Therefore, the conversion from the saprophytic mycelial phase to the parasitic yeast phase is the first step in pathogenesis. Although conversion in culture is often a lengthy process, it appears to be relatively rapid in the presence of macrophages. Phagocytosis of microconidia and small mycelial fragments takes place within 4 to $6 \mathrm{~h}$, and conversion to the yeast phase is apparent at $24 \mathrm{~h}(43)$ and complete within $72 \mathrm{~h}$ (57).

Transition to the yeast phase is an absolute requirement for progression of histoplasmosis, as demonstrated by pathogenic strains treated with $p$-chloromercuriphenylsulfonic acid (76). These strains are irreversibly altered so that they can no longer convert to the yeast phase but continue to grow in vitro as mycelia, even at $37^{\circ} \mathrm{C}$. When mice were inoculated with $p$-chloromercuriphenylsulfonic acid-treated mycelia, no signs of histoplasmosis appeared and no fungi or granulomas were detectable at autopsy. Together, these results imply that the mycelium-to-yeast transition is not essential for growth at higher temperatures, but that the transition is required for a successful infection.

The classic laboratory conversion of the mycelial phase to the yeast phase is triggered by temperature, and this change has obvious connections with temperatures in the soil versus those in mammalian hosts. The other major recognized factor that governs the phase transition is cysteine. Because of work with the Downs strain, cysteine was thought to have two roles. The first is to provide the sulfhydryl groups that are required for the phase transition. Early in the transition, an NADH-dependent cystine reductase appears and is responsible for the generation of these sulfhydryl groups (72). More recent work (77) has indicated that only the Downs strain (and possibly other class 1 strains) has this requirement for cysteine during the transition at $37^{\circ} \mathrm{C}$; class 2 strains do not require cysteine or other sulfhydryl groups for the transition, unless unusually high temperatures (over $40^{\circ} \mathrm{C}$ ) trigger cysteine-activated respiratory shunt pathways (77). 
These observations again point to strain- and class-specific strategies for adaptation to changing environments.

The second role of cysteine is as an essential nutrient of the yeast phase. Various $\boldsymbol{H}$. capsulatum enzymes are implicated in this dependence on cysteine, including a sulfite reductase and a cysteine oxidase. The expression of sulfite reductase is temperature dependent, and because it is repressed in yeast cells, they cannot synthesize cysteine (8). Cysteine oxidase (61) appears during phase transition (73) and is probably involved in the metabolism of cysteine for the emerging yeast phase. Even the kinetics of cysteine transport is both temperature and phase dependent, favoring yeast cells at $37^{\circ} \mathrm{C}(50)$. All of these points emphasize cysteine's important role in signalling a highly regulated conversion of $\boldsymbol{H}$. capsulatum from saprophyte to parasite.

\section{Interactions with Professional Phagocytic Cells}

The most consistent feature of histoplasmosis is the ability of $H$. capsulatum to parasitize macrophages. Once ingested and inside the phagosome, the yeasts continue to multiply at a rate comparable to that in cell-free liquid culture medium (44). This is true even when the yeasts are exposed to specific antibody and complement (45). Thus, in contrast to their usual role in eliminating microorganisms from the lung, macrophages provide an environment for continued $\boldsymbol{H}$. capsulatum growth and facilitate dissemination to other tissues.

Other professional phagocytes may also be involved as permissive hosts of $\boldsymbol{H}$. capsulatum, although the available data are not consistent. For example, polymorphonuclear leukocytes (PMNs) from guinea pigs have been shown to destroy $H$. capsulatum (46), while a more recent study with human PMNs demonstrates that the organisms survive intracellularly (103). However, given the very short life span of PMNs in vivo, a more productive habitat for a slow-growing organism would be the long-lived and migratory macrophage.

The intracellular environment provides unique survival advantages for $\boldsymbol{H}$. capsulatum, including avoidance of nonspecific clearance mechanisms (e.g., the mucociliary escalator) and access to other organs via the bloodstream and lymphatics. There may also be special nutritional advantages to intracellular growth. For example, $\boldsymbol{H}$. capsulatum growth in vitro depends on the production of hydroxamic acid siderophores to sequester iron (12). Dilute cultures with a low concentration of siderophores have poor plating efficiency unless supplemented with these siderophores (13) or with an alternative source of solubilized iron (125). Siderophores would also be diluted out in extracellular environments such as plasma, in which high-affinity chelating systems such as transferrin effectively create a low free-iron environment that inhibits $H$. capsulatum growth (116). In the confines of a phagosome, it is more likely that siderophores could achieve adequate concentrations to sequester sufficient iron for yeast cell growth.

Despite the advantages of intracellular growth, the environment within professional phagocytes is complex, changing, and generally hostile to microorganisms. Intracellular pathogens must avoid or overcome a series of obstacles in order to enter without simultaneous or subsequent destruction. In the case of $\boldsymbol{H}$. capsulatum, the evolution of efficient survival strategies is especially surprising, since the yeast phase is not required for the survival and proliferation of this organism in the soil.

Adherence and phagocytosis. Recent studies with a variety of immunological techniques have identified receptors for the binding of $\boldsymbol{H}$. capsulatum to professional phagocytes. $\boldsymbol{H}$. capsulatum yeasts bind to the CD18 family of receptors on human monocyte-derived macrophages (11), alveolar macrophages (83), and PMNs (106); microconidia also bind to this receptor (83). Consistent with these observations, the kinetics of yeast ingestion was most rapid for cultured macrophages and the slowest for peripheral blood monocytes, which have much lower expression of CD18 receptors (83).

The CR3 receptor (a member of the CD18 receptor family) has been well characterized with respect to binding complement component $\mathrm{C} 3 \mathrm{bi}$, but the binding of $\boldsymbol{H}$. capsulatum shows distinct differences. For example, particles coated with C3bi bind to macrophages but do not signal phagocytosis (126), yet the binding and ingestion of $\boldsymbol{H}$. capsulatum are linked (83). In addition, the cytoskeletal requirements for binding and ingestion of $\mathrm{C} 3 \mathrm{bi}$-coated particles are different from those of $\boldsymbol{H}$. capsulatum (83). One explanation is that additional adhesin-receptor relationships may be involved, as suggested by a recent study showing $\boldsymbol{H}$. capsulatum adherence to a membrane glycosphingolipid (53). Binding appears to be specific for lactosylceramide, since yeasts do not bind to analogs with substitutions or modifications of the lactosyl residue. Whether lactosylceramide is important for $H$. capsulatum adherence to phagocytes or to other host cells is not yet clear.

Avoidance of oxidative killing mechanisms. Coordinate with phagocytosis of microorganisms, phagocytes release a variety of toxic oxygen metabolites: superoxide, hydrogen peroxide, singlet oxygen, and hydroxyl radicals $(2,14,54$, 58). Not surprisingly, a variety of pathogenic organisms thwart these defenses. For example, virulent Nocardia asteroides resists oxidative killing mechanisms because it releases superoxide dismutase and possesses catalase (3, 32). While $\boldsymbol{H}$. capsulatum strains have various amounts of catalase, the levels of this enzyme in different strains do not correlate with virulence (49). Instead, $H$. capsulatum elicits little or no oxidative response from murine resident peritoneal macrophages $(27,124)$ or from human PMNs $(106)$. This phenomenon has been observed with a number of other pathogens, including Toxoplasma gondii (122). In the case of $H$. capsulatum, simultaneous incubation of live yeasts with a known stimulus of the oxidative burst (e.g., zymosan) showed no inhibition of superoxide release by macrophages or PMNs $(27,106)$. These findings imply that $\boldsymbol{H}$. capsulatum neither immediately inhibits the respiratory burst nor scavenges the anion. Instead, the yeast simply fails to trigger the release of superoxide. Furthermore, $H$. capsulatum may also have long-lasting effects on the macrophage's ability to mount a subsequent oxidative burst in response to other stimuli $(123,124)$.

Not all available data agree regarding the stimulation of a respiratory burst: one study with human monocyte-derived macrophages did show evidence of an oxidative burst in response to $\boldsymbol{H}$. capsulatum (11). Some of these discrepancies may relate to the species and differentiated state of the host cells chosen or to differences in the particular assays used. Nevertheless, most studies are consistent with the binding of $H$. capsulatum to the CR3 receptor, one of the members of the CD18 family described above. Binding of CR3 by C3bicoated particles fails to elicit an oxidative burst (127); $\boldsymbol{H}$. capsulatum may be binding to CR3 by a similar mechanism. These results were obtained with nonopsonized yeasts, and Bullock and Wright (11) showed that macrophages, a possible source of complement components, were not locally 
opsonizing yeasts. Therefore, it is likely that an adhesin on the $H$. capsulatum surface is responsible for mimicking the effects of $\mathrm{C} 3 \mathrm{bi}$ binding to $\mathrm{CR} 3$ receptors.

All of this suggests that $H$. capsulatum needs to avoid exposure to toxic oxygen radicals for successful parasitism, and in vitro studies support this concept. $H$. capsulatum conidia and yeasts are killed in vitro by a combination of $\mathrm{H}_{2} \mathrm{O}_{2}$, halide, and myeloperoxidase (48) that corresponds to the makeup of one of the PMN's oxidative antimicrobial systems. Still, there may be other mechanisms by which $\boldsymbol{H}$. capsulatum survives oxygen-dependent killing mechanisms. For example, antibody-opsonized $\boldsymbol{H}$. capsulatum yeasts will stimulate a respiratory burst in macrophages (124) and in PMNs (106), presumably because of uptake by Fc-mediated phagocytosis instead of CR3. However, as mentioned earlier, opsonization has no effect on the ability of organisms to proliferate inside macrophages (45).

Life in the phagosome. A successful intracellular parasite must cope not only with the onslaught of toxic oxygen metabolites but also with phagocytic vesicles that acidify $(34,42,75)$ and eventually fuse with lysosomes. Accordingly, some pathogens (such as $T$. gondii [111]) have evolved ways to minimize the acidification that occurs. It is not known how $H$. capsulatum responds to acidification within macrophages, but earlier studies have described the effects of acidic and basic conditions on growth in vitro (6). The yeasts can grow in medium with a starting $\mathrm{pH}$ of between 5 and 10 . However, during such growth, H. capsulatum modulates its environment so that the $\mathrm{pH}$ of the medium comes close to neutral. Perhaps this occurs in vivo as well, allowing the organism to "buffer" its phagosomal compartment. A similar phenomenon may occur when Mycobacterium tuberculosis, which is known to release ammonia (40), grows inside macrophages.

Intracellular survival is also predicated on avoiding destruction by lysosomal components. Some organisms must be resistant to these killing mechanisms since they survive within phagolysosomes (e.g., Leishmania spp. [18]). Fusion of lysosomes with $\boldsymbol{H}$. capsulatum-laden phagosomes was first suggested in the ultrastructural analysis of Dumont and Robert (26), but this was not a quantitative study and used no specific markers. Using fluoresceinated dextran to monitor the fate of lysosomes in macrophages, Eissenberg et al. (29) demonstrated normal kinetics of fusion with $H$. capsulatum-containing phagosomes. Acridine orange labeling confirmed this observation in macrophages (117) and in macrophagelike cell lines $(29,117)$, with the only exception occurring at very high ratios of yeasts to macrophages. These results imply that $\boldsymbol{H}$. capsulatum yeast cells either resist or inactivate the fungicidal activities of lysosomes.

Although it is not clear how $\boldsymbol{H}$. capsulatum can thrive in this hostile intracellular microenvironment, there is no apparent deficiency in the fungicidal power of macrophage lysosomes. This was demonstrated by the exposure of $\boldsymbol{H}$. capsulatum to a lysosomal extract from rabbit alveolar macrophages, which was able to inhibit yeast protein synthesis and cause extensive ultrastructural damage within 24 $h$ (15). The implication is that this extract does not accurately duplicate the phagolysosomal compartment and that some modification induced by or in $\boldsymbol{H}$. capsulatum is responsible for its survival and proliferation. In this context, it is intriguing that $\boldsymbol{H}$. capsulatum antigens appear to become associated with the phagosomal membrane in infected macrophages (87).

The proliferation of $\boldsymbol{H}$. capsulatum within macrophages is terminated with the development of cell-mediated immunity and the corresponding activation of macrophages. This leads to growth inhibition but not outright killing of the intracellular yeasts (47). The extensive topic of macrophage activation by the host immune response is beyond the scope of this article, since such activation is involved more with host (rather than pathogen) adaptations and responses in histoplasmosis. However, the reader is referred to recent reviews of this topic $(23,128)$.

\section{Interactions with Nonprofessional Phagocytic Cells}

During histoplasmosis the macrophage is the most commonly observed infected cell type. However, the failure of activated cells to actually kill $\boldsymbol{H}$. capsulatum may result in a persistent infection of the host. While it is possible that the organisms do not spread beyond the macrophage reservoir, they may occasionally escape to some nonmacrophage cell in which they can multiply.

$H$. capsulatum can enter and replicate in nonprofessional phagocytes both in vivo and in vitro. In the first case ever described, Darling (21) noted yeasts within both alveolar epithelial cells and endothelial cells. Infected endothelial cells $(20,21,107)$ can theoretically facilitate the lymphohematogenous spread of the organism. In vitro, HeLa cells (an epithelial line), L cells (a fibroblast line), and embryonic fibroblastlike cells from horse and chick tissues are all nonprofessional phagocytes that can serve as hosts for the yeast $(44,92-94)$.

These observations, coupled with the variety of tissues infected during disseminated disease, led Eissenberg et al. (30) to explore the possibility that nonprofessional phagocytes lining the respiratory tract might act as hosts for this microbe. They found that organisms lacking $\alpha$-(1,3)-glucan in their cell walls readily entered hamster trachea epithelial (HTE) cells in vitro. Other than G217B (which is virulent but from class 2 [see subsection, Genetic Taxonomy]), these organisms were all spontaneous smooth-colony derivatives of rough strains (see subsection, Spontaneous Avirulent Variants). Yeasts with the rough phenotype only rarely entered HTE cells.

\section{Emergence of Variants}

The rare $\alpha$-(1,3)-glucan-positive (rough) yeasts which were internalized by HTE cells subsequently underwent a dramatic change. Nearly half of the ingested organisms no longer expressed $\alpha-(1,3)$-glucan at $24 \mathrm{~h}$ postinoculation (30). Enriching for the rare internalized yeasts resulted in isolates lacking $\alpha-(1,3)$-glucan and growing as smooth colonies on solid medium.

These results suggest that various mammalian cells may trigger phenotypic changes in $H$. capsulatum after it is inhaled. Just as macrophages $(43,57)$ and HeLa cells $(67)$ both facilitate a rapid phase transition from the mycelium to the yeast phase, HTE cells may stimulate metabolic or morphological alterations or both in $H$. capsulatum yeast cells. In both of these examples, entry into animal cells induces mechanisms by which the organism rapidly converts from one phenotype to another.

Physiological alterations may facilitate growth in one cell type (e.g., HTE cells) as well as alter the interaction of the fungus with other host cells (e.g., macrophages). In contrast to their parental strains (30), neither the smooth variants described above (see subsection, Spontaneous Avirulent Variants) nor those selected for their ability to grow in HTE cells can kill P388D1.D2 macrophagelike cells. Instead, 
these yeasts assume large or unusual shapes (allomorphs [28]) inside these cells as well as inside resident peritoneal macrophages from either mice or rats. Furthermore, the smooth variants establish persistent infections within P388D1.D2 cells (30). Representatives of three separate genetic classes, all containing $\alpha-(1,3)$-glucan in their cell walls, are able to spawn both types of variants (30). This includes the only strain of $H$. capsulatum var. duboisii examined. Thus, the capacity for phenotypic switching appears to be broadly conserved within the species.

Allomorphs may be the in vitro analog of the large and oddly shaped yeasts that have been described in histological sections for decades (see subsection, Classical Versus duboisii Varieties). Pulmonary tissues rarely contain large forms, but many other organs of infected humans and animals do $(7,20,25,52,80,85)$. Organisms growing on infected tissue explants (108) also often have these enlarged shapes. In a study of 18 strains of $\boldsymbol{H}$. capsulatum, including 4 of the variety duboisii, all but 2 produced large forms with varied frequency when grown on solid medium (25).

Some host factor may play a role in inducing allomorphs in vivo. When infecting hamsters, yeasts from most of the 18 strains in the aforementioned study (25) assumed a variety of sizes and shapes. Noting that hamsters express various levels of susceptibility to histoplasmosis, O'Hern (85) found that $95 \%$ of the animals showing some resistance to disease had large yeasts in their livers. These enlarged organisms were not found in any of the hamsters that died. Explants from several organs began to inhibit the growth of yeasts in culture at times correlating with the appearance of these large organisms. An inhibitory factor was subsequently characterized and found to be specific for $H$. capsulatum (86). Thus, these enlarged forms seem to correlate with an effective suppression of in vivo infection.

\section{CONCLUSIONS AND MODEL}

$H$. capsulatum clearly has a profound ability to adapt to a variety of environments. On the most basic level, dimorphism provides it with two obviously distinct developmental forms, each of which exists predominantly under one set of circumstances (i.e., in the soil or in the mammalian host). However, the literature reviewed here suggests that the capacity for adaptation extends well beyond this most blatant example. The following model proposes how the responsiveness of $\boldsymbol{H}$. capsulatum to its surroundings and the variation among isolates could result in the variety of manifestations of histoplasmosis.

(i) The microenvironment within the soil selects for or induces certain traits. The distribution of $H$. capsulatum within a wide range of geographical locations illustrates how well this species acclimates to its surroundings. This ability may be especially important within the region of endemicity in the United States, which experiences wide swings in temperature and moisture. Natural strain variation as well as adaptations most likely result in the coexistence of multiple strains or variants with distinct phenotypes. Routine culture methods may identify only a subset of these phenotypes, e.g., the A and B mycelium types (see subsection, Mycelial Subtypes) and red-pigmented strains (81). Current soil testing techniques may be unable to detect some strains, e.g., the class 1 isolates, despite clinical evidence that their ecological niches overlap with other culturable strains (see subsections, Epidemiology and Genetic Taxonomy). If conditions temporarily favor one phenotype over another or if massive disruption of the soil occurs, there may be aero- solization of fungi to which the majority of the populace lacks immunity. This may explain the occurrence of epidemics in areas where the disease is endemic.

(ii) The traits found within the population of inhaled fungi influence the severity of disease in healthy hosts. Some strains are clearly more virulent than others $(1,51,68,84)$, just as some strains or their variants are more proficient at killing macrophages (see subsections, Spontaneous Avirulent Variants and Emergence of Variants). Large numbers of the more virulent organisms in the inhalant probably result in acute histoplasmosis. The less virulent fungi presumably initiate an inapparent or mild infection that nonetheless renders the individual reactive to histoplasmin.

Macrophages may be persistently infected by these less virulent organisms (see subsection, Emergence of Variants), even if they make up only part of the inoculum. Chronic or latent disease could then be established. Epithelial cells can be infected in vitro by virulent organisms from class 2 and by the avirulent variants described here. As discussed earlier, all of these strains lack $\alpha-(1,3)$-glucan in their cell walls. Perhaps in vivo some similar cell type becomes infected, thus establishing a reservoir of organisms that might play a role in persistent disease.

(iii) Variants arise subsequent to inhalation of the fungus. Even when a "pure" inoculum consisting of only one strain is inhaled, variants may arise in response to the microenvironment found within the host. An occasional interaction with respiratory epithelial cells could induce variants similar to those described above (see subsection, Emergence of Variants). These yeasts might then establish a persistent infection of either macrophages or nonprofessional phagocytes.

The alacrity with which certain strains respond to their environments may also differ. For example, since there is little evidence of lung involvement following infection by $\boldsymbol{H}$. capsulatum var. duboisii, perhaps this organism rapidly produces variants that either quickly escape the lung or cause an inapparent infection therein. These organisms might also be more prone to form large yeasts as well as to initiate long-term infections.

Unusual conditions within the host could also foster adaptations by the yeasts. Certain types of human histocompatibility antigens may coincide with physiological characteristics that either directly encourage colonization of the eyes or induce or select for variants that are more apt to do so (see subsection, Ocular histoplasmosis). Likewise, the altered environment within the lungs of patients with bullous or centrilobular emphysema may be particularly hospitable for certain phenotypes (see subsection, Chronic pulmonary histoplasmosis). This might explain why aberrant mycelial types are often found in patients with chronic pulmonary disease (65). Alternatively, these individuals may be more easily infected by a strain that is less virulent for healthy people.

(iv) The pathological features of reactivation histoplasmosis should in part reflect the characteristics of both the host and the inoculum during the original infection. As proposed here, the initial infection is influenced by the characteristics of the inhaled organisms, the variants that arise subsequent to infection, and the overall health and immune status of the host. Thus, the organs harboring latent infections and the yeasts present at those sites may differ widely between individuals. These differences will be reflected in the symptoms that arise upon reactivation. This may at least partially explain why there has been no consistent pathology associated with histoplasmosis in patients with AIDS $(62,71)$. 


\section{FINAL REMARKS}

The literature reviewed here emphasizes the diverse environments to which $H$. capsulatum has responded with either adaptations or natural variations. Many of these environments are in a continual state of flux. Weather, as well as the activities of humans and other animals, affects conditions in the soil. The health and state of the immune response at the time of infection influence the microenvironments in specific organs and inside host cells. Likewise, the genetic makeup of the host may further determine the conditions confronting the infecting fungus. It is suggested here that both natural variation within the species and the capacity of individual organisms to adapt have made this fungus a widespread and successful pathogen.

\section{ACKNOWLEDGMENT}

Our laboratory's research on $\boldsymbol{H}$. capsulatum-host cell interactions has been supported by Public Health Service grant AI 25584 from the National Institutes of Health.

\section{REFERENCES}

1. Anderson, K. L., and S. Marcus. 1969. Variability in virulence of strains of Histoplasma capsulatum. Am. Rev. Respir. Dis. 99:608-609.

2. Babior, B. M. 1978. Oxygen-dependent microbial killing by phagocytes. N. Engl. J. Med. 298:659-668.

3. Beaman, B. L., S. M. Scates, S. E. Moring, R. Deem, and H. P. Misra. 1983. Purification and properties of a unique superoxide dismutase from Nocardia asteroides. J. Biol. Chem. 258:9196.

4. Berliner, M. D. 1968. Primary subcultures of Histoplasma capsulatum. I. Macro and micro-morphology of the mycelial phase. Sabouraudia 6:111-118.

5. Berliner, M. D. 1971. Biological implications of morphological variants in Histoplasma capsulatum primary isolates, p. 21-29. In L. Ajello, E. W. Chick, and M. L. Furcolow (ed.), Histoplasmosis. Proceedings of the Second National Conference. Charles C Thomas, Publisher, Springfield, Ill.

6. Berliner, M. D. 1973. Histoplasma capsulatum: effects of $\mathrm{pH}$ on the yeast and mycelial phases in vitro. Sabouraudia 11:267270.

7. Binford, C. H. 1955. Histoplasmosis. Tissue reactions and morphologic variations of the fungus. Am. J. Clin. Pathol. 25:25-36.

8. Boguslawski, G., J. M. Akagi, and L. G. Ward. 1976. Possible role for cysteine biosynthesis in conversion from mycelial to yeast form of Histoplasma capsulatum. Nature (London) 261:336-338.

9. Borok, R. 1980. The mycelial status and reversibility in Histoplasma capsulatum. Sabouraudia 18:249-253.

10. Braley, R. E., T. A. Meredith, T. M. Aaberg, S. A. Koethe, and J. A. Witkowski. 1978. The prevalence of HLA-B7 in presumed ocular histoplasmosis. Am. J. Ophthalmol. 85:859-861.

11. Bullock, W. E., and S. D. Wright. 1987. Role of the adherencepromoting receptors, CR3, LFA-1, and P150,95, in binding of Histoplasma capsulatum by human macrophages. J. Exp. Med. 165:195-210.

12. Burt, W. R. 1982. Identification of coprogen B and its breakdown products from Histoplasma capsulatum. Infect. Immun. 35:990-996.

13. Burt, W. R., A. L. Underwood, and G. L. Appleton. 1981. Hydroxamic acid from Histoplasma capsulatum that displays growth factor activity. Appl. Environ. Microbiol. 42:560-563.

14. Bus, J. S., and J. E. Gibson. 1983. Mechanisms of superoxide radical-mediated toxicity. J. Toxicol. Clin. Toxicol. 19:689697.

15. Calderone, R. A., and E. Peterson. 1979. Inhibition of amino acid uptake and incorporation into Histoplasma capsulatum by a lysosomal extract from rabbit alveolar macrophages. J.
Reticuloendothel. Soc. 26:11-19.

16. Campbell, C. C. 1965. The epidemiology of histoplasmosis. Ann. Intern. Med. 62:1333-1336.

17. Campbell, C. C., and M. D. Berliner. 1973. Virulence differences in mice of type A and B Histoplasma capsulatum yeasts grown in continuous light and total darkness. Infect. Immun. 8:677-678.

18. Chang, K.-P. 1983. Cellular and molecular mechanisms of intracellular symbiosis in leishmaniasis. Int. Rev. Cytol. Suppl. 14:267-305.

19. Craig, E. L., and T. Suie. 1974. Histoplasma capsulatum in human ocular tissue. Arch. Ophthalmol. 91:285-289.

20. Crumrine, R. M., and J. F. Kessel. 1931. Histoplasmosis (Darling) without splenomegaly. Am. J. Trop. Med. 11:435449.

21. Darling, S. T. 1906. A protozoan general infection producing pseudotubercles in the lungs and focal necroses in the liver, spleen, and lymphnodes. JAMA 46:1283-1285.

22. Davies, S. F., M. Khan, and G. A. Sarosi. 1978. Disseminated histoplasmosis in immunologically suppressed patients: occurrence in a nonendemic area. Am. J. Med. 64:94-100.

23. Deepe, G. S., Jr., and W. E. Bullock. 1988. Histoplasmosis: a granulomatous inflammatory response, p. 733-748. In J. I. Gallin, I. M. Goldstein, and R. Snyderman (ed.), Inflammation: basic principles and clinical correlates. Raven Press, Ltd., New York.

24. Domer, J. E. 1971. Monosaccharide and chitin content of cell walls of Histoplasma capsulatum and Blastomyces dermatitidis. J. Bacteriol. 107:870-877.

25. Drouhet, E., and J. Schwarz. 1956. Comparative studies with 18 strains of Histoplasma. Morphology in tissues and virulence of African and American strains. J. Lab. Clin. Med. 47:128139.

26. Dumont, A., and A. Robert. 1970. Electron microscopic study of phagocytosis of Histoplasma capsulatum by hamster peritoneal macrophages. Lab. Invest. 23:278-286.

27. Eissenberg, L. G., and W. E. Goldman. 1987. Histoplasma capsulatum fails to trigger release of superoxide from macrophages. Infect. Immun. 55:29-34.

28. Eissenberg, L. G., S. Poirier, and W. E. Goldman. 1990. Persistence of avirulent Histoplasma capsulatum yeasts in an altered morphology within P388D1 macrophages, p. 424. Abstr. Annu. Meet. Am. Soc. Microbiol. 1990. American Society for Microbiology, Washington, D.C.

29. Eissenberg, L. G., P. H. Schlesinger, and W. E. Goldman. 1988. Phagosome-lysosome fusion in P388D1 macrophages infected with Histoplasma capsulatum. J. Leukocyte Biol. 43:483-491.

30. Eissenberg, L. G., J. L. West, J. P. Woods, and W. E. Goldman. 1991. Infection of P388D1 macrophages and respiratory epithelial cells by Histoplasma capsulatum: selection of avirulent variants and their potential role in persistent histoplasmosis. Infect. Immun. 59:1639-1646.

31. Feman, S. S., and R. H. Tilford. 1985. Ocular findings in patients with histoplasmosis. JAMA 253:2534-2537.

32. Filice, G. A., B. L. Beaman, J. A. Krick, and J. S. Remington. 1980. Effects of human neutrophils and monocytes on Nocardia asteroides: failure of killing despite occurrence of the oxidative metabolic burst. J. Infect. Dis. 142:432-438.

33. Gass, M., and G. S. Kobayashi. 1969. Histoplasmosis. An illustrative case with unusual vaginal and joint involvement. Arch. Dermatol. 100:724-727.

34. Geisow, M. J. 1984. Fluorescein conjugates as indicators of subcellular pH. Exp. Cell Res. 150:29-35.

35. Godfrey, W. A., R. Sabates, and D. E. Cross. 1978. Association of presumed ocular histoplasmosis with HLA-B7. Am. J. Ophthalmol. 85:854-858.

36. Goldstein, B. G., and H. Buettner. 1983. Histoplasmic endophthalmitis: a clinicopathologic correlation. Arch. Ophthalmol. 101:774-777.

37. Goodman, D. H. 1973. Systemic fungal infection complications in asthmatic patients treated with steroids. Ann. Allergy 31: 205-214.

38. Goodman, N. L., and H. W. Larsh. 1967. Environmental 
factors and growth of Histoplasma capsulatum in soil. Mycopathol. Mycol. Appl. 33:145-156.

39. Goodwin, R. A., Jr., F. T. Owens, J. D. Snell, W. W. Hubbard, R. D. Buchanan, R. T. Terry, and R. M. Des Prez. 1976. Chronic pulmonary histoplasmosis. Medicine (Baltimore) 55: 413-452.

40. Gordon, A. H., P. D. Hart, and M. R. Young. 1980. Ammonia inhibits phagosome-lysosome fusion in macrophages. Nature (London) 256:79-80.

41. Graybill, J. R. 1988. Histoplasmosis and AIDS. J. Infect. Dis. 158:623-626.

42. Heiple, J. M., and D. L. Taylor. 1982. $\mathrm{pH}$ changes in pinosomes and phagosomes in the ameba, Chaos carolinensis. J. Cell Biol. 94:143-149.

43. Hempel, H., and N. L. Goodman. 1975. Rapid conversion of Histoplasma capsulatum, Blastomyces dermatitidis, and Sporothrix schenckii in tissue culture. J. Clin. Microbiol. $1: 420-424$.

44. Howard, D. H. 1964. Intracellular behavior of Histoplasma capsulatum. J. Bacteriol. 87:33-38.

45. Howard, D. H. 1965. Intracellular growth of Histoplasma capsulatum. J. Bacteriol. 89:518-523.

46. Howard, D. H. 1973. Fate of Histoplasma capsulatum in guinea pig polymorphonuclear leukocytes. Infect. Immun. 8:412-419.

47. Howard, D. H. 1973. Further studies on the inhibition of Histoplasma capsulatum within macrophages from immunized animals. Infect. Immun. 8:577-581.

48. Howard, D. H. 1981. Comparative sensitivity of Histoplasma capsulatum conidiospores and blastospores to oxidative antifungal systems. Infect. Immun. 32:381-387.

49. Howard, D. H. 1983. Studies on the catalase of Histoplasma capsulatum. Infect. Immun. 39:1161-1166.

50. Howard, D. H., N. Dabrowa, V. Otto, and J. Rhodes. 1980. Cysteine transport and sulfite reductase activity in a germination-defective mutant of Histoplasma capsulatum. J. Bacteriol. 141:417-421.

51. Howell, A., Jr., and G. F. Kipkie. 1950. Studies on experimental histoplasmosis. J. Lab. Clin. Med. 36:547-554.

52. Hutton, J. P., J. B. Durham, D. P. Miller, and E. D. Everett. 1985. Hyphal forms of Histoplasma capsulatum: a common manifestation of intravascular infections. Arch. Pathol. Lab. Med. 109:330-332.

53. Jiminez-Lucho, V., V. Ginsburg, and H. C. Krivan. 1990. Cryptococcus neoformans, Candida albicans, and other fungi bind specifically to the glycosphingolipid lactosylceramide (Gal $\beta 1-4 G l c \beta 1-1 C e r)$, a possible adhesion receptor for yeasts. Infect. Immun. 58:2085-2090.

54. Johnston, R. B., Jr. 1978. Oxygen metabolism and the microbicidal activity of macrophages. Fed. Proc. 37:2759-2764.

55. Kabli, S., J. R. Koschmann, G. W. Robertstad, J. Lawrence, L. Ajello, and K. Redetzke. 1986. Endemic canine and feline histoplasmosis in El Paso, Texas. J. Med. Vet. Mycol. 24:4150.

56. Kanetsuna, F., L. M. Carbonell, F. Gil, and I. Azuma. 1974. Chemical and ultrastructural studies on the cell walls of the yeast and mycelial forms of Histoplasma capsulatum. Mycopathologia 54:1-13.

57. Kimberlin, C. L., A. R. Hariri, H. O. Hempel, and N. L. Goodman. 1981. Interactions between Histoplasma capsulatum and macrophages from normal and treated mice: comparison of the mycelial and yeast phases in alveolar and peritoneal macrophages. Infect. Immun. 34:6-10.

58. Klebanoff, S. J. 1982. Oxygen-dependent cytotoxic mechanisms of phagocytes, p. 111-162. In J. I. Gallin and A. S. Fauci (ed.), Advances in host defense mechanisms, vol. 1. Raven Press, New York.

59. Klimpel, K. R., and W. E. Goldman. 1987. Isolation and characterization of spontaneous avirulent variants of Histoplasma capsulatum. Infect. Immun. 55:528-533.

60. Klimpel, K. R., and W. E. Goldman. 1988. Cell walls from avirulent variants of Histoplasma capsulatum lack $\alpha-(1,3)$ glucan. Infect. Immun. 56:2997-3000.
61. Kumar, V., B. Maresca, M. Sacco, R. Goewert, G. S. Kobayashi, and G. Medoff. 1983. Purification and characterization of a cysteine dioxygenase from the yeast phase of Histoplasma capsulatum. Biochemistry 22:762-768.

62. Kurtin, P. J., D. S. McKinsey, M. R. Gupta, and M. Driks. 1990. Histoplasmosis in patients with acquired immunodeficiency syndrome. Am. J. Clin. Pathol. 93:367-372.

63. Kwon-Chung, K. J., M. S. Bartlett, and L. J. Wheat. 1984 Distribution of the two mating types among Histoplasma capsulatum isolates obtained from an urban histoplasmosis outbreak. Sabouraudia 22:155-157.

64. Kwon-Chung, K. J., R. J. Weeks, and H. W. Larsh. 1974 Studies on Emmonsiella capsulata (Histoplasma capsulatum). II. Distribution of the two mating types in 13 endemic states of the United States. Am. J. Epidemiol. 99:44-49.

65. Larsh, H. W. 1971. Variation among isolates of Histoplasma capsulatum, p. 34-37. In L. Ajello, E. W. Chick, and M. C. Furcolow (ed.), Histoplasmosis. Proceedings of the Second National Conference. Charles C. Thomas, Publisher, Springfield, Ill.

66. Larsh, H. W. 1975. Pathogenesis of experimental cryptococcosis and histoplasmosis induced by the airborne route, $\mathrm{p}$. 63-71. In Mycoses. Pan American Health Organization, Washington, D.C.

67. Larsh, H. W., A. Hinton, and S. L. Silberg. 1956. Conversion and maintenance of Histoplasma capsulatum in tissue culture. Proc. Soc. Exp. Biol. Med. 93:612-615.

68. Louria, D. B., N. Feder, W. Mitchell, and C. W. Emmons. 1959. Influence of fungus strain and lapse of time in experimental histoplasmosis and of volume of inoculum in cryptococcosis upon recovery of the fungi. J. Lab. Clin. Med. 53:311-319.

69. Mahvi, T. A. 1970. Factors governing the epidemiology of Histoplasma capsulatum in soil. Mycopathol. Mycol. Appl. 41:167-176.

70. Makley, T. A., E. L. Craig, and K. Werling. 1983. Histopathology of ocular histoplasmosis. Int. J. Ophthalmol. Clin. 23:1-18.

71. Mandell, W., D. M. Goldberg, and H. C. Neu. 1986. Histoplasmosis in patients with the acquired immune deficiency syndrome. Am. J. Med. 81:974-978.

72. Maresca, B., E. Jacobson, G. Medoff, and G. Kobayashi. 1978. Cystine reductase in the dimorphic fungus Histoplasma capsulatum. J. Bacteriol. 135:987-992.

73. Maresca, B., A. M. Lambowitz, V. B. Kumar, G. A. Grant, G. S. Kobayashi, and G. Medofi. 1981. Role of cysteine in regulating morphogenesis and mitochondrial activity in the dimorphic fungus Histoplasma capsulatum. Proc. Natl. Acad. Sci. USA 78:4596-4600.

74. Mariat, F., and G. Segretain. 1956. Étude mycologique d'une histoplasmose spontanee du singe africain Cynocephalus Babuin. Ann. Instit. Pasteur (Paris) 91:874-891.

75. McNeil, P. L., L. Tanasugarn, J. B. Meigs, and D. L. Taylor. 1983. Acidification of phagosomes is initiated before lysosomal enzyme activity is detected. J. Cell Biol. 97:692-702.

76. Medoff, G., G. S. Kobayashi, A. Painter, and S. Travis. 1987. Morphogenesis and pathogenicity of Histoplasma capsulatum. Infect. Immun. 55:1355-1358.

77. Medoff, G., B. Maresca, A. M. Lambowitz, G. Kobayashi, A, Painter, M. Sacco, and L. Carratu. 1986. Correlation between pathogenicity and temperature sensitivity in different strains of Histoplasma capsulatum. J. Clin. Invest. 78:1638-1647.

78. Menges, R. W., M. L. Furcolow, L. A. Selby, R. T. Habermann, and C. D. Smith. 1967. Ecologic studies of histoplasmosis. Am. J. Epidemiol. 85:108-118.

79. Meredith, T. A., R. E. Smith, and R. J. Duquesnoy. 1980. Association of HLA-DRw2 antigen with presumed ocular histoplasmosis. Am. J. Ophthalmol. 89:70-76.

80. Moore, M. 1955. Morphologic variation in tissue of the organisms of the blastomycoses and of histoplasmosis. Am. J. Pathol. 31:1049-1063.

81. Morris, P. R., A. A. Terreni, and A. F. DiSalvo. 1986. Redpigmented Histoplasma capsulatum-an unusual variant. J. Med. Vet. Mycol. 24:231-233.

82. Murray, P. J. S., and R. A. Sladden. 1965. Disseminated 
histoplasmosis following long-term steroid therapy for reticulosarcoma. Br. Med. J. (Clin. Res.) 2:631-632.

83. Newman, S. L., C. Bucher, J. Rhodes, and W. E. Bullock. 1990. Phagocytosis of Histoplasma capsulatum yeasts and microconidia by human cultured macrophages and alveolar macrophages: cellular cytoskelton requirement for attachment and ingestion. J. Clin. Invest. 85:223-230.

84. Nielsen, H. S. 1966. Variation in lipid content of strains of Histoplasma capsulatum exhibiting different virulence properties for mice. J. Bacteriol. 91:273-277.

85. O'Hern, E. M. 1961. Resistance of hamsters in infections with Histoplasma capsulatum. J. Immunol. 87:728-736.

86. O'Hern, E. M. 1967. Studies on histoplasmosis. III. Cross reactions and characterization of Histoplasma and Blastomy ces inhibitory factors. Mycopathol. Mycol. Appl. 31:193-208.

87. Patino, M. M., J. T. Hansen, and J. R. Graybill. 1986 Immunocytochemical staining of Histoplasma capsulatum at the electron microscopic level. Mycopathologia 94:157-161.

88. Paya, C. V., P. E. Hermans, R. E. Van Scoy, R. E. Ritts, Jr., and H. A. Homburger. 1987. Repeatedly relapsing disseminated histoplasmosis: clinical observations during long-term follow-up. J. Infect. Dis. 156:308-312.

89. Paya, C. V., G. D. Roberts, and F. R. Cockerill III. 1987. Transient fungemia in acute pulmonary histoplasmosis: detection by new blood-culturing techniques. J. Infect. Dis. 156: 313-315.

90. Pine, L., and C. J. Boone. 1968. Cell wall composition and serological reactivity of Histoplasma capsulatum serotypes and related species. J. Bacteriol. 96:789-798.

91. Procknow, J. J. 1971. Reinfection histoplasmosis, p. 252-259. In L. Ajello, E. W. Chick, and M. L. Furclow (ed.), Histoplasmosis. Proceedings of the Second National Conference. Charles C. Thomas, Publisher, Springfield, Ill.

92. Randall, C. C., and A. L. Hackney. 1953. Observations on human tissue cultures naturally infected by Histoplasma capsulatum. Am. J. Pathol. 29:861-867.

93. Randall, C. C., and D. L. McVickar. 1951. Histoplasma capsulatum in tissue culture. Proc. Soc. Exp. Biol. Med. 77:150-158.

94. Randall, C. C., and D. J. Turner. 1953. Cultivation of yeast in Earle's "L" strain mouse cells in vitro. Proc. Soc. Exp. Biol. Med. 83:584-585

95. Reiss, E. 1977. Serial enzymatic hydrolysis of cell walls of two serotypes of yeast-form Histoplasma capsulatum with $\alpha(1 \rightarrow 3)$ glucanase, $\beta(1 \rightarrow 3)$-glucanase, pronase, and chitinase. Infect. Immun. 16:181-188.

96. Rippon, J. W. 1988. Histoplasmosis (Histoplasmosis capsulati), p. 381-432. In Medical mycology. The pathogenic fungi and the pathogenic actinomycetes. The W. B. Saunders Co. Philadelphia.

97. Rippon, J. W. 1988. Histoplasmosis duboisii, p. 424-432. In Medical mycology. The pathogenic fungi and the pathogenic actinomycetes. The W. B. Saunders Co., Philadelphia.

98. San-Blas, G., and L. M. Carbonell. 1974. Chemical and ultrastructural studies on the cell walls of the yeastlike and mycelial forms of Histoplasma farciminosum. J. Bacteriol. 119:602611.

99. San-Blas, G., D. Ordaz, and F. J. Yegres. 1978. Histoplasma capsulatum: chemical variability of the yeast cell wall. Sabouraudia 16:279-284.

100. San-Blas, G., F. San-Blas, E. Ormaechea, and L. E. Serrano. 1977. Cell wall analysis of an adenine-requiring mutant of the yeast-like form of Paracoccidioides brasiliensis strain IVIC $\mathrm{Pb}$. Sabouraudia 15:297-303.

101. San-Blas, G., F. San-Blas, and L. E. Serrano. 1977. Hostparasite relationships in the yeastlike form of Paracoccidioides brasiliensis strain IVIC Pb9. Infect. Immun. 15:343-346.

102. San-Blas, G., and D. Vernet. 1977. Induction of the synthesis of cell wall $\alpha$-1,3-glucan in the yeastlike form of Paracoccidioides brasiliensis strain IVIC $\mathrm{Pb} 9$ by fetal calf serum. Infect. Immun. 15:897-902.

103. Schaffner, A., C. E. Davis, T. Schaffner, M. Markert, H. Douglas, and A. I. Braude. 1986. In vitro susceptibility of fungi to killing by neutrophil granulocytes discriminates between primary pathogenicity and opportunism. J. Clin. Invest. 78: 511-524.

104. Schlaegel, T. F., Jr. 1983. The concept of invisible choroiditis in the ocular histoplasmosis syndrome. Int. Ophthalmol. Clin. 23:55-63.

105. Schlech, W. F., L. J. Wheat, J. L. Ho. M. L. V. French, R. J. Weeks, R. B. Kohler, C. E. Deane, H. E. Eitzen, and J. D. Band. 1983. Recurrent urban histoplasmosis, Indianapolis, Indiana, 1980-1981. Am. J. Epidemiol. 118:301-312.

106. Schnur, R. A., and S. L. Newman. 1990 . The respiratory burst response to Histoplasma capsulatum by human neutrophils. Evidence for intracellular trapping of superoxide anion. $\mathrm{J}$. Immunol. 144:4765-4772.

107. Scholz, R., W. R. Green, R. Kutys, J. Sutherland, and R. D. Richards. 1984. Histoplasma capsulatum in the eye. 91:11001104.

108. Schwartz, J. 1953. Giant forms of Histoplasma capsulatum in tissue explants. Am. J. Clin. Pathol. 23:898-903.

109. Schwarz, J. 1958. The pathogenesis of histoplasmosis. Trans. N.Y. Acad. Sci. 20:541-548.

110. Schwarz, J. 1971. The pathogenesis of histoplasmosis, p. 244-251. In L. Ajello, E. W. Chick, and M. C. Furcolow (ed.) Histoplasmosis. Proceedings of the Second National Conference. Charles C. Thomas, Publisher, Springfield, Ill.

111. Sibley, L. D., J. L. Krahenbuhl, G. M. W. Adams, and E. Weidner. 1986. Toxoplasma modifies macrophage phagosomes by secretion of a vesicular network rich in surface proteins. $\mathrm{J}$. Cell Biol. 103:867-874.

112. Smith, R. E., J. I. Macy, C. Parrett, and J. Irvine. 1978 Variations in acute multifocal histoplasmic choroiditis in the primate. Invest. Ophthalmol. Vis. Sci. 17:1005-1018.

113. Spitzer, E. D., E. J. Keath, S. J. Travis, A. A. Painter, G. S. Kobayashi, and G. Medoff. 1990. Temperature-sensitive variants of Histoplasma capsulatum isolated from patients with acquired immunodeficiency syndrome. J. Infect. Dis. 162:258261.

114. Spitzer, E. D., B. A. Lasker, S. J. Travis, G. S. Kobayashi, and G. Medoff. 1989. Use of mitochondrial and ribosomal DNA polymorphisms to classify clinical and soil isolates of Histoplasma capsulatum. Infect. Immun. 57:1409-1412.

115. Stone, M. M., L. M. Frenkel, and D. H. Howard. 1990. Histoplasmosis after multiple trauma. Pediatr. Infect. Dis. J. 9:747-749.

116. Sutcliffe, M. C., A. M. Savage, and R. H. Alford. 1980. Transferrin-dependent growth inhibition of yeast-phase Histoplasma capsulatum by human serum and lymph. J. Infect. Dis. 142:209-219.

117. Taylor, M. L., M. E. Espinosa-Schoelly, R. Iturbe, B. Rico, J. Casasola, and F. Goodsaid. 1989. Evaluation of phagolysosome fusion in acridine orange stained macrophages infected with Histoplasma capsulatum. Clin. Exp. Immunol. 75:466-470.

118. Tewari, R. P., and F. J. Berkhout. 1972. Comparative pathogenicity of albino and brown types of Histoplasma capsulatum for mice. J. Infect. Dis. 125:504-508.

119. Vanek, J., and J. Schwarz. 1971. The gamut of histoplasmosis. Am. J. Med. 50:89-104.

120. Vincent, R. D., R. Goewert, W. E. Goldman, G. S. Kobayashi, A. M. Lambowitz, and G. Medoff. 1986. Classification of Histoplasma capsulatum isolates by restriction fragment polymorphisms. J. Bacteriol. 165:813-818.

121. Walker, J., and E. T. C. Spooner. 1960. Natural infection of the African baboon Papio Papio with the large-cell form of Histoplasma. J. Pathol. Bacteriol. 80:436-440.

122. Wilson, C. B., V. Tsai, and J. S. Remington. 1980. Failure to trigger the oxidative metabolic burst by normal macrophages: possible mechanism for survival of intracellular pathogens. J. Exp. Med. 151:328-346.

123. Wolf, J. E., A. L. Abegg, S. J. Travis, G. S. Kobayashi, and J. R. Little. 1989. Effects of Histoplasma capsulatum on murine macrophage functions: inhibition of macrophage priming, oxidative burst, and antifungal activities. Infect. Immun. 57:513-519. 
124. Wolf, J. E., V. Kerchberger, G. S. Kobayashi, and J. R. Little. 1987. Modulation of the macrophage oxidative burst by Histoplasma capsulatum. J. Immunol. 138:582-586.

125. Worsham, P. L., and W. E. Goldman. 1988. Quantitative plating of Histoplasma capsulatum without addition of conditioned medium or siderophores. J. Med. Vet. Mycol. 26:137143.

126. Wright, S. D., and F. M. Griffin, Jr. 1985. Activation of phagocytic cells' C3 receptors for phagocytosis. J. Leukocyte
Biol. 38:327-339.

127. Wright, S. D., and S. C. Silverstein. 1983. Receptors for C3b and $\mathrm{C} 3$ bi promote phagocytosis but not the release of toxic oxygen from human phagocytes. J. Exp. Med. 158:2016-2023.

128. Wu-Hsieh, B., and D. H. Howard. Histoplasmosis. In H. Friedman, J. A. Murphy, and M. Bendinelli (ed.), Fungal infections and immune responses, in press. Plenum Press, New York. 